\title{
Joint Agency Commercial Imagery Evaluation (JACIE)
}

Remote sensing data are vital to understanding the physical world and to answering many of its needs and problems. The United States Geological Survey's (USGS) Remote Sensing Technologies (RST) Project, working with its partners, is proud to sponsor the annual Joint Agency Commercial Imagery Evaluation (JACIE) Workshop to help understand the quality and usefulness of remote sensing data. The JACIE program was formed in 2001 to leverage U.S. Federal agency resources for the characterization of commercial remote sensing data. These agencies sponsor and co-chair JACIE:

- U.S. Geological Survey (USGS)

- National Aeronautics and Space Administration (NASA)

- National Geospatial-Intelligence Agency (NGA)

- U.S. Department of Agriculture (USDA)

JACIE is an effort to coordinate data assessments between the participating agencies and partners and communicate the knowledge and results of the quality and utility of the remotely sensed data available for government and private use.

JACIE agencies and partners analyze remote sensing commercial data products to provide scientists and other users with independent verification of data quality. Each agency brings unique resources and strengths to this task. JACIE evaluations have been instrumental in generating many improvements to remote sensing product quality as well as enhancing the working relationships between government and the commercial remote sensing industry.

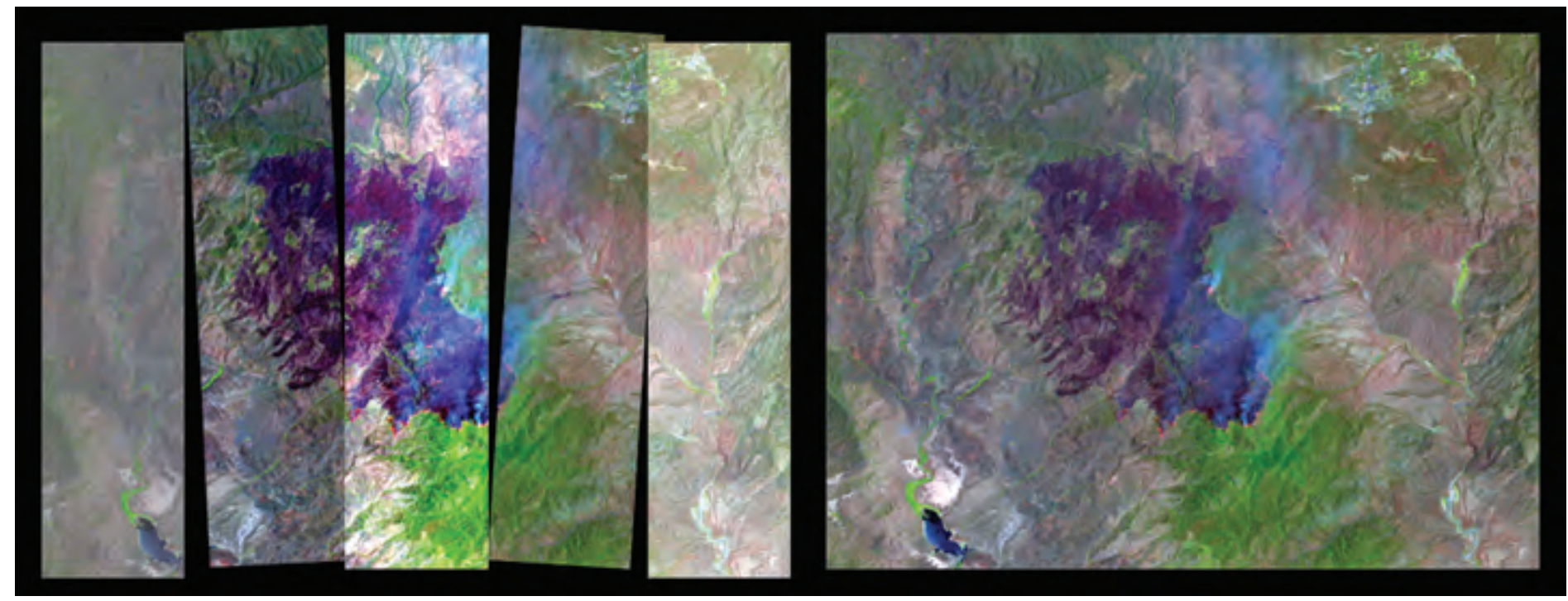

This image symbolically brings segmented imagery into view through radiometric and geometric calibration. 
Geo-positional, spatial, and radiometric quality are three primary areas for JACIE image characterizations. Combined, these properties help to describe the quality of image data and strongly affect the usability of the data for a myriad of Earth science applications and studies.

The JACIE group hosts an annual Civil Commercial Imagery Evaluation Workshop, a forum where the growing body of available remote sensing data research and assessments results are presented to several hundred government and industry attendees. This highly regarded and inde-

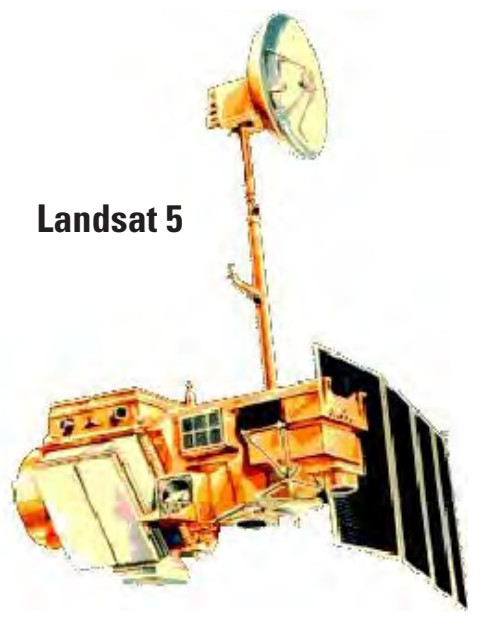
pendent workshop affords the opportunity for presenters to exchange information regarding the characterization and application of commercial imagery used by the public sector. Presenters also have the opportunity to provide updates for current and future enhancements to existing sensors and promote new sensor uses and data products.

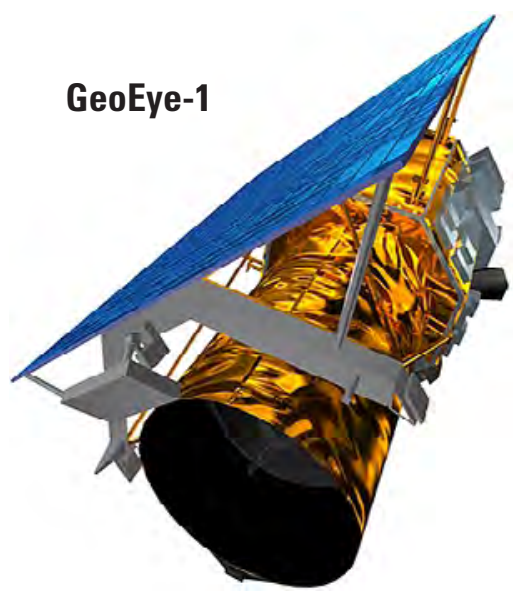

Analyses of satellite and digital aerial systems are presented each year at the JACIE workshops. The USGS RST Project and partner Federal agencies will continue to evaluate and assess current and new sources of data and present them at future workshops to the remote sensing community.

The USGS RST Project continues research into the quality and usability of remotely sensed data from satellite and airborne platforms, whether public or private, foreign or domestic. Satellites illustrated here are some of the many evaluated by the USGS RST Project along with numerous aerial platforms. In addition, current assessments of new technology digital image and LiDAR (Light Detection and Ranging) system datasets are available. For more information, please contact Greg Stensaas at the USGS Earth Resources Observation and Science (EROS)

Center.

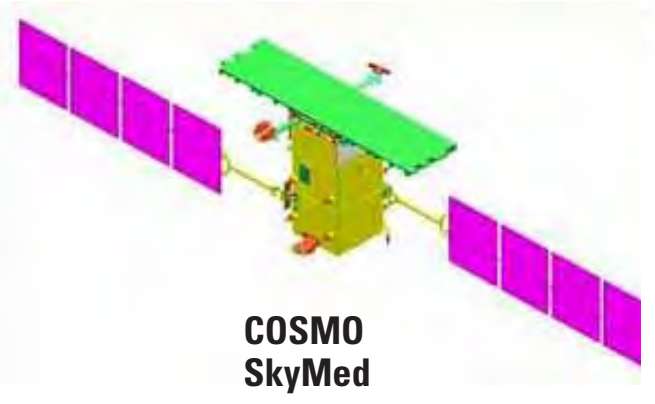

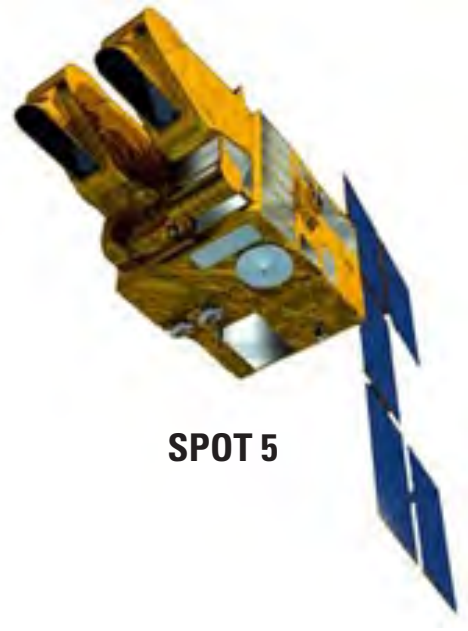

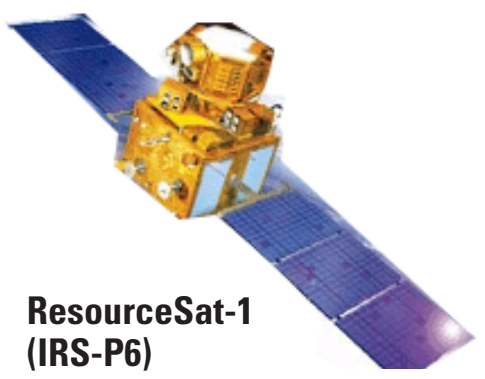

(IRS-P6)
For more information contact:

Greg Stensaas

USGS EROS

Mundt Federal Building

Sioux Falls, SD 57198

605-594-2569

stensaas@usgs.gov

or visit http://calval.cr.usgs.gov/ 